\title{
Os desafios da repartição: um estudo de caso em uma empresa multinacional do Sul do Brasil
}

\author{
The challenges of repatriation: a case study in \\ a multinational company the south of Brazil
}

\author{
Shalimar Gallon ${ }^{1}$ \\ Angela Beatriz Busato Scheffer ${ }^{2}$ \\ Ives Gallon ${ }^{3}$
}

\section{Resumo}

A expatriação é o processo que ocorre quando um empregado assume um cargo pela empresa em um país estrangeiro, e a repatriação compreende a etapa em que o expatriado volta para o país de origem. Com o objetivo de analisar o processo de repatriação, as expectativas dos empregados na repatriação e identificar os desafios que esse processo impõe para as organizações, desenvolveu-se um estudo de caso na empresa Alpha, na qual foram realizadas 21 entrevistas: duas com representantes da área de Recursos Humanos e 19 com expatriados e repatriados. A partir da transcrição das entrevistas, foi realizada a análise de conteúdo, a fim de auxiliar na interpretação dos dados coletados. A pesquisa mostra que a empresa precisa de políticas e práticas mais estruturadas, apesar de ter um programa de expatriação há 12 anos, pois a internacionalização tomou uma dimensão maior do que a organização estava preparada para suportar. Outro achado é que os repatriados, ao retornarem, passam a dar mais valor ao desenvolvimento de habilidades e da

1 Doutoranda em Administração na Universidade Federal do Rio Grande do Sul (UFRGS). Universidade Federal do Rio Grande do Sul - Endereço: Rua Washington Luiz, 855 - Sala: 415. Centro. CEP: 90010-460. Porto Alegre - RS - Brasil. E-mail: shalimargallon@hotmail.com telefone: (55) 81125331

2 Doutora em Administração pela Universidade Federal do Rio Grande do Sul (UFRGS), professora adjunta da Universidade Federal do Rio Grande do Sul (UFRGS). Endereço: Rua Washington Luiz, 855 - Sala: 415. Centro. CEP: 90010-460. Porto Alegre - RS - Brasil. E-mail: angela.scheffer@ufrgs.br telefone: (51) 33083536

3 Graduado em Administração pela Universidade Federal de Santa Maria (UFSM). Universidade do Pampa (Unipampa). Endereço: Avenida Tiarajú, 810, Prédio: A1, Sala: 217, Bairro: Ibirapuita, CEP: 97546-550, Alegrete - RS - Brasil. E-mail: ivesgallon@unipampa.edu.br Telefone: (55) 34218400 
carreira profissional, independentemente da organização em que o indivíduo se encontra. A carreira organizacional fica em segundo plano, principalmente porque a empresa não vem elaborando um planejamento para aproveitá-los em posições que demandem mais responsabilidades, como as que tinham na missão.

Palavras-chave: Expatriação. Repatriação. Carreira. Recursos Humanos Internacional.

\section{Abstract}

Expatriation is the process which occurs when an employee of an organization takes a position in a foreign country, while repatriation is the moment in which the expatriate returns to the home country. In order to analyze the repatriation process and the employees' expectations regarding the repatriation, and identify the challenges that this process generates to the organization, a case study was developed at Alpha Company, in which 21 people were interviewed: two persons representing the Human Resources and 19 employees, including expatriates and repatriates. In order to analyze the data collected a content analysis was conducted based on the transcript of the interviews. The research shows that, even though the organization has the expatriation program for 12 year, it needs more structured policies and practices because the internationalization developed more than the organization was prepared to support. Another finding is that the repatriates give more value to their internal career when they are back to their home countries. They value more the development of skills and the professional career, regardless the organization. The organizational career stays in the background, especially since the company does not have a structure to allocate the repatriates in positions that require more responsibilities, as it was required abroad.

Keywords: Expatriation. Repatriation.Career.International Human Resources.

\section{Introdução}

A estratégia de enviar empregados para as subsidiárias, quando toma âmbito internacional, passa a compreender o processo de expatriação, que ocorre quando o empregado assume um cargo pela empresa em um país estrangeiro, pelo período de um ou dois anos (CALIGIURI, 2000; DUTRA, 2002). A expatriação normalmente ocorre quando as empresas buscam expandir novos mercados, aumentar a participação dos mercados, internacionalizar a gestão, elevar o nível de coordenação e controle de suas unidades geograficamente dispersas, 
e aumentar a diversidade estratégica da Gestão de Recursos Humanos (GRH) frente aos mercados globais (FREITAS, 2010; FREITAS; DANTAS, 2011;TANURE et al., 2007). Esse contexto revela a importância de estudar a expatriação como um processo que pode auxiliar a empresa a alcançar esses objetivos e desenvolver-se internacionalmente.

Neste estudo, a expatriação é entendida como um processo amplo, dividido em três momentos, os quais devem ser bem estruturados para que se alcance o sucesso. Essas três etapas são: (1) a preparação para a missão, (2) a missão em si e (3) a volta da missão. A última etapa consiste na repatriação. Os repatriados, pela vivência e pelo conhecimento que adquiriram do contexto cultural, do mercado e dos clientes, podem ajudar a empresa a estabelecer e expandir os negócios em âmbito internacional. Esses empregados experimentam como é a atuação da empresa em outros países e, assim, fazem parte de uma rede social global que pode dar continuidade/melhoria ao desenvolvimento das estratégias internacionais. Os repatriados têm, portanto, importante papel na organização, uma vez que podem acelerar a transferência de conhecimentos das subsidiárias para a matriz e vice-versa, auxiliando no amadurecimento internacional da empresa (GALLON; SCHEFFER, 2013). Por essas razões, as empresas devem ver os repatriados como um significativo investimento de capital humano e devem se preocupar com seu retorno (DERESKY, 2004; LAZAROVA; CALIGIURI, 2001).

Deresky (2004) e Tung (1988) abordam um fator importante na repatriação: a adaptação do empregado ao seu antigo cotidiano - o denominado "choque cultural reverso". Esse choque faz com que o executivo sinta-se esquecido dentro da organização e passe a ter dificuldades em sua readaptação, além de ocorrerem novas expectativas em relação à sua carreira dentro da empresa. A adaptação da família também pode ser demorada, pois há possibilidade de se terem perdido os contatos sociais ou de emprego.

Entende-se que a repatriação é um processo complexo de renegociação e readaptação (organizacional e social) tanto para o expatriado como para sua família. As expectativas que surgem para os empregados que retornam podem ultrapassar a realidade, na expectativa 
de posição e remuneração melhores, como as que foram oferecidas na experiência internacional, bem como autonomia e reconhecimento dos superiores. Surge, então, como questão deste estudo: quais as expectativas e os desafios que emergem, para a empresa e para os empregados, a partir da experimentação em um processo de repatriação?

Muitas empresas não valorizam o repatriamento, o que pode estar relacionado à falta de uma ação mais estratégica ou de práticas e políticas de expatriação que contemplem de modo mais eficaz a repatriação. Nota-se, portanto, a relevância de estudos sobre repatriação nas empresas. Dessa maneira, o objetivo desse estudo foi analisar o processo de repatriação em uma empresa brasileira, a fim de levantar as expectativas dos empregados na repatriação e identificar os desafios que esse processo impõe para as organizações.

Para levantar os estudos sobre repatriação, Bianchi (2011) analisou 29 artigos em 11 periódicos, no período de 2000 a 2010. A autora mostra que, na América Latina, há poucos estudos realizados sobre expatriação. Sobretudo no Brasil, busca-se, nas teorias internacionais, a base teórica para as pesquisas realizadas. Consequentemente, não há a devida compreensão do contexto, visto que a realidade das empresas internacionais não é convergente com aquela na qual as empresas brasileiras estão inseridas, sendo necessário debater e estudar casos brasileiros. O levantamento de Barretos et al. (2011) vai ao encontro dos achados de Bianchi (2011) e relata que a internacionalização da GRH é um dos temas emergentes, com tendência a aumento nas pesquisas.

O presente estudo está estruturado com as seguintes seções: elucidação do referencial teórico sobre repatriação, visto que esse é o foco da pesquisa; procedimentos metodológicos; análise dos dados sobre repatriação na empresa Alpha; considerações finais.

\section{Entendendo a repatriação}

Frente aos desafios impostos às empresas que buscam novos mercados no exterior, surge a necessidade de desenvolvimento de uma 
Gestão de Recursos Humanos Internacional (GRHI) para planejar e conduzir atividades que melhor influenciem na conduta dos indivíduos e os seus esforços por estabelecer e desenvolver uma estratégia internacional (TAYLOR et al., 1996). Envolve lidar com o gerenciamento eficaz de pessoas de diferentes nacionalidades, podendo contribuir com os resultados das missões no exterior.

Desse modo, com a internacionalização das empresas, a expatriação torna-se um processo central, tornando-se um tema importante de estudo. Entretanto, como referido anteriormente, deve ser percebido como um processo amplo, que envolve fases igualmente importantes. O planejamento da ida, a missão em si e a repatriação devem ter igual atenção, o que nem sempre acontece. O recente levantamento realizado por Bianchi (2011) corrobora com tal afirmação ao mostrar que a GRHI tem como principal foco a preparação para a saída do profissional, e não o seu retorno.

A repatriação deve ser entendida como mais do que o simples retorno de um empregado ao seu país de origem depois de uma missão internacional estendida (HERMAN; TRETRICK, 2009); é um processo complexo, envolvendo renegociação, readaptação, reconstrução de redes profissionais e reancoragem da carreira na empresa. Além de a perda da autossatisfação e da autoconfiança nas habilidades gerenciais do trabalhador e o custo de ter de volta um empregado insatisfeito e desmotivado para o trabalho atual, há outros aspectos relacionados às dificuldades da repatriação. Muitos expatriados de missões específicas, com objetivos e estratégias a cumprir, ao retornarem, ficam à espera de outra oportunidade de trabalho. Eles acham complexo desistir da autonomia que tinham quando estavam na missão internacional. Quando isso acumula com a perda de status social e dos benefícios financeiros que eles recebiam em função da missão, a repatriação pode se tornar um processo complicado (LAZAROVA; CALIGIURI, 2001; MCCALL; HOLLENBECK, 2003; TANURE et al., 2007; SUUTUARI; BREWSTER, 2003).

As expatriações englobam as exigências do mercado de trabalho atual e tendem a gerar nos empregados experiências que afetam suas 
expectativas de evolução pessoal e profissional, de representações sociais, de avaliação de suas próprias competências (HOMEM; DELLAGNELO, 2006). O repatriado adquire novas percepções com a experiência internacional, pois além de ter a possibilidade de desenvolver a liderança e adquirir novas habilidades técnicas, o indivíduo muda a sua visão de mundo. Com a missão, o executivo passa a redefinir sua identidade e sua família passa igualmente por esse processo de amadurecimento.

O estudo de Lee e Liu (2006) com americanos mostra que 50\% dos repatriados tiveram dificuldades de ajustamento no retorno ao país de origem. Quando o indivíduo retorna para a organização, pode ser que esse "novo sujeito" não se ajuste mais à empresa, o que também pode ser um dos motivos que levam os repatriados a se demitirem e procurarem outra empresa que valorize sua experiência e habilidades adquiridas (SUUTARI; BREWSTER, 2003).

Além das mudanças que aconteceram com o expatriado, a organização também sofreu alterações. Algumas pessoas foram contratadas e outras demitidas; os processos, o layout e os procedimentos também mudaram. Isso pode ser outro fator que faça com que o expatriado se sinta desconfortável ou que não pertence mais aquele lugar. Isso está relacionado com as práticas e políticas que a empresa tem para lidar com uma interculturalidade organizacional. Se ela busca se tornar internacional, precisa estar preparada para gerenciar diferentes aprendizados e culturas.

A mobilidade dos empregados não se refere somente ao âmbito internacional, e sim ao intranacional (CRAIDE et al., 2010). Craide et al. (2010) apontam a necessidade de as empresas desenvolverem formas de gestão que atendam às demandas dos profissionais que se deslocam para o exterior ou dentro de um mesmo país, pois as dificuldades de recolocação são similares em função da interação entre pessoas de culturas regionais distintas de um mesmo país no ambiente organizacional. Os autores ainda enfatizam que essas pessoas que se deslocam intranacionalmente também buscam o desenvolvimento de 
suas carreiras, tal como os expatriados. Essas similaridades apontam para a necessidade de políticas e práticas de $\mathrm{RH}$ que sejam apropriadas para essa intraculturalidade dentro das organizações.

A empresa Brookfield Global Relocation Services (2010) realizou uma pesquisa com 120 empresas de pequeno, médio e grande porte em todo mundo e observou que $38 \%$ dos expatriados deixam a empresa no primeiro ano de repatriação - esse índice era de 35\% no relatório de 2009 - e ao final do segundo ano de expatriação, $22 \%$ dos repatriados deixam a empresa. A alta rotatividade entre os repatriados pode vincular esse processo a um aspecto negativo, fazendo com que outros empregados sejam resistentes a aceitar uma expatriação, comprometendo as estratégias globais da empresa (LEE; LIU, 2006; TANURE et al., 2007).

A repatriação tem sido atrelada à carreira e à adaptação do retorno do empregado, no entanto, muitas vezes, essa etapa pode ser vista como o descarrilamento da carreira de um empregado. Embora seja inevitável considerar o retorno para casa como uma transição suave, nem sempre é assim. Os expatriados, ao retornarem, percebem que perderam suas redes de contatos de negócio e seus amigos, que seu país natal não é mais o mesmo de quando o deixaram e, por mais doloroso que seja, poucas pessoas ao redor dos expatriados se importam com isso. Suas condições de vida podem decair sem os benefícios financeiros já citados anteriormente. Eles podem retornar para cargos inferiores e com responsabilidades reduzidas e sentir que a organização não aproveita ou não aprecia o que aprenderam (LAZAROVA; CALIGIURI, 2001; MCCALL; HOLLENBECK, 2003; PEREIRA et al., 2004; SUUTUARI; BREWSTER, 2003)

Além da perda do capital humano e financeiro, a organização perde também em competitividade no mercado de atuação, pois, geralmente, os expatriados que se demitem são contratados por empresas concorrentes (DERESKY, 2004; LAZAROVA; CALIGIURI, 2001; SUUTARI; BREWSTER, 2003). Assim, a organização estaria preparando os empregados para seus concorrentes e, consequentemente, fornecendo a eles vantagem competitiva. 
A pesquisa de Tung (1998) mostra que grande parte dos expatriados percebe a experiência internacional como impacto positivo na sua carreira. Essa percepção pode estar relacionada com a carreira interna do indivíduo, a qual envolve a aquisição de habilidades, desenvolvimento pessoal e reforço da carreira profissional, mesmo que essa carreira não seja desenvolvida dentro da organização em que o expatriado se encontra no momento (STAHL et al., 2002). A carreira interna envolve um senso subjetivo que se refere ao lugar que a pessoa deseja chegar com o seu trabalho, enquanto a carreira externa aborda o avanço do empregado dentro da hierarquia da empresa (SCHEIN, 1996).

Os estudos de Stahl et al. (2002) mostram que $89 \%$ dos repatriados acreditam que a experiência internacional tem um impacto positivo em sua carreira, mesmo que isso não melhore sua posição dentro da organização. Isso mostra que os expatriados, quando aceitam a missão internacional, já estão pensando na sua carreira interna, analisando as habilidades que a missão vai agregar a eles, e não à organização. Esse contexto "sem fronteiras" é um cenário provável que as atividades de investimento na carreira, através do apoio de práticas da organização, podem incentivar a retenção após o repatriamento, mas isso não implica que necessariamente vai influenciar positivamente na lealdade do empregado em longo prazo (LAZAROVA; CALIGIURI, 2001).

A experiência internacional demanda dos sujeitos uma disposição e uma abertura para o novo que cada vez mais tem sido valorizada nos dias de hoje. Assim, como aponta Freitas (2009), a mobilidade, entendida como um conjunto complexo de disposições e competências que coloca o indivíduo em interação com o diferente de si, pode ser vista como um novo capital simbólico no mundo organizacional, seja a partir da circulação mundial de profissionais, por meio de processos de expatriação, e a de empresas, a partir de processos de relocalização, fusões e aquisições. É própria de um mundo de incertezas, que exige respostas adaptáveis, mutáveis, ágeis, flexíveis, numa abertura para o mundo que exige dos profissionais e das empresas um contínuo estado de movimento. Craide et al. (2010) reforçam essa ideia, referindo que a mobilidade pode ser nacional ou internacional e é uma imposição do 
novo cenário organizacional. Empresas valorizam, estimulam e exigem tal atributo no currículo de seus empregados.

Essa disposição e abertura às novas experiências pode ser entendida como fruto de uma lógica de trabalho que implica em maior complexidade, desempenho constante e desenvolvimento contínuo de competências, havendo uma construção em torno da noção de que os profissionais devem se responsabilizar e investir mais diretamente no desenvolvimento contínuo de suas carreiras, dentro da propagada necessidade de o indivíduo continuamente investir em si próprio. Fontenelle (2007, p. 7) em uma perspectiva crítica, apresenta a ideia de "vida como business", tônica presente no atual modo de viver. Assim, entende-se o citado impacto que é percebido pelos repatriados entre a noção de carreira e a experiência da expatriação (GALLON; SCHEFFER, 2013).

Isso sugere que alguns problemas de repatriação não são adequadamente considerados pela área de Recursos Humanos, e isso pode fazer com que o processo de expatriação aconteça com menor frequência (LAZAROVA; CALIGIURI, 2001; STAHL et al., 2002). Observando essa questão estratégica do capital humano, as formas de prever maior retenção após a repatriação tornam-se um importante desafio para as organizações internacionalizadas (BLACK; GREGERSEN, 1999).

Um bom planejamento de repatriação começa com o esforço para gerir as expectativas dos expatriados, mesmo antes de eles saírem para a missão. As organizações devem fazer uma tentativa de reter os expatriados, correspondendo às suas expectativas durante e depois da missão internacional (LAZAROVA; CALIGIURI, 2001). Assim, quando os repatriados percebem que têm mais apoio de sua organização, mostramse mais comprometidos com a empresa e provavelmente continuarão nela após a missão internacional.

Algumas organizações adotam práticas de assistência aos executivos no gerenciamento de suas expectativas em relação ao seu trabalho e à sua vida particular, antes de irem para a expatriação. Uma 
dessas práticas é o planejamento da carreira, pois se o expatriado sabe de antemão quais suas perspectivas dentro da organização, a fase de repatriação tende a ser mais realista, com menos peso no impacto entre expectativa e realidade (SUUTUARI; BREWSTER, 2003). Essa prática configura-se como um dos caminhos para as organizações reterem seus expatriados.

A complexidade do contexto global aumenta as chances de que a organização cometa vários equívocos, na maior parte evitáveis, os quais podem contribuir para o descarrilamento de uma carreira do repatriado. A ausência de feedback, o pouco monitoramento, a tolerância à falhas e a falta de apoio são alguns dos problemas citados por Mccall e Hollenbeck (2003).

Por isso, a gestão de desempenho da expatriação é uma prática importante. Rego e Cunha (2009) enfatizam a atenção organizacional em relação ao avaliador, pois se o avaliador encontra-se frequentemente em país distinto do país em que o expatriado está a exercer a missão, a empresa deve ter a sensibilidade de criar mecanismos para que o resultado da missão chegue ao país de retorno do expatriado. Além disso, o avaliador deve ter sensibilidade para as particularidades da cultura e da empresa em que o expatriado exerceu as funções (REGO; CUNHA, 2009).

O estudo de Lima e Braga (2010) relata o levantamento de políticas e práticas de recursos humanos utilizadas pelas empresas no Brasil para garantir o sucesso do processo de repatriação e retenção dos repatriados. É revelado que as ações das empresas no processo de repatriação não são ações estratégicas e estão relacionadas ao suporte operacional ao repatriado. Os resultados da pesquisa mostram que as principais políticas e práticas de recursos humanos para a repatriação são: manter o expatriado informado sobre as mudanças que ocorrem na organização durante a expatriação, pagamentos de viagens ao país de origem durante a expatriação, verba para realização da mudança e recolocação do expatriado no mercado de trabalho se não houver um posto apropriado no retorno. Como pode ser observado, ainda não são 
muitas as práticas de $\mathrm{RH}$ para o momento da repatriação, bem como pouco existe em termos de retenção do expatriado.

Os dados do citado estudo mostram que as empresas pesquisadas justificam a falta de políticas para a repatriação por estarem mais focadas em enviar expatriados para o exterior, e não em repatriar, ou porque o número de repatriados é muito baixo, ou ainda porque os brasileiros não têm dificuldades de adaptação ou expatriação, nem no retorno ao Brasil. Tal pesquisa mostra a necessidade de se olhar para os três momentos de expatriação, bem como direcionar práticas para que todas essas fases sejam bem conduzidas.

Outro estudo que busca analisar a gestão de expatriados com ênfase na questão da adaptação na repatriação foi o conduzido por Osman-Gani e Hyder (2008), na região da Ásia. Tal estudo buscou compreender as práticas de $\mathrm{RH}$ relativas à formação e ao desenvolvimento da adaptação efetiva dos gestores internacionais na repatriação. Os resultados mostram que $60 \%$ das empresas não têm nenhum programa formal de repatriamento para seus gestores internacionais, sendo as oportunidades de desenvolvimento de carreira e o suporte na mudança física as características preferenciais a serem incluídas no desenvolvimento de uma política de repatriamento. A maioria das empresas parece pensar que, pelo fato de os empregados estarem voltando para seu próprio país, não há necessidade de fornecer curso de reciclagem. Palestras, workshops e seminários dentro do programa de treinamento foram sinalizados como práticas importantes, havendo preferência para que os programas sejam conduzidos por empregados de escritório residencial, com experiência em repatriação.

Para que a organização seja capaz de acumular as competências e o conhecimento dos repatriados, ela deve cultivar uma visão global e uma cultura corporativa que apoiemos valores e a experiência internacional dos expatriados (LAZAROVA; CALIGIURI, 2001). A valorização da expatriação, além de contribuir com o desenvolvimento estratégico da empresa, pode diminuir as demissões após a repatriação, pois a organização estará valorizando o empregado, o que torna o tema relevante para estudos. 


\section{Procedimentos metodológicos}

Esta pesquisa consiste em um estudo de caso realizado na empresa Alpha (nome fictício dado para a organização em estudo, a fim de preservar sua identificação), do setor metalúrgico no Rio Grande do Sul. A coleta de dados foi realizada por meio de entrevistas, com roteiro semiestruturado, organizado tendo em vista os objetivos do estudo e alicerçado na literatura consultada. O roteiro passou por um teste-piloto com três pessoas: um repatriado sem vínculo com a empresa e dois repatriados da organização. As entrevistas foram realizadas durante os meses de junho, julho e agosto de 2010, e foram realizadas cinco visitas a duas unidades da empresa.

Além dos responsáveis pela expatriação na área de $\mathrm{RH}$, foram definidos 4 grupos de entrevistados, conforme elucida o Quadro 1. Vale ressaltar que a empresa possui como política que o contrato dos expatriados deve ser pelo período de um ano, podendo ser renovado por mais um ano; portanto, o empregado que fica um ano fora da empresa é considerado um expatriado, sendo esse o recorte da pesquisa para a determinação de quem seria um expatriado.

Quadro 1 - Grupos de Entrevistados

\begin{tabular}{|l|c|c|}
\hline Grupo & Situação & Participantes \\
\hline Grupo 1 & Estão no início da expatriação & 4 \\
\hline Grupo 2 & Estão maior tempo em expatriação & 4 \\
\hline Grupo 3 & Repatriados & 7 \\
\hline Grupo 4 & Repatriados desligados da empresa & 4 \\
\hline $\begin{array}{l}\text { Área de Recursos } \\
\text { Humanos }\end{array}$ & Representantes da área de expatriação & 2 \\
\hline
\end{tabular}

Fonte: Elaboração dos autores (2013)

No total, foram entrevistadas 21 pessoas: dois responsáveis pela área de expatriação, quatro expatriados do Grupo 1, quatro expatriados do Grupo 2, sete repatriados do Grupo 3 e quatro ex-empregados repatriados do Grupo 4. Com relação aos entrevistados, não houve 
distinção de sexo, escolaridade, faixa etária, renda, cargo e país de destino.

As entrevistas, na primeira fase, foram realizadas com duas pessoas da área de $\mathrm{RH}$ responsáveis pela expatriação, buscando-se identificar as práticas e políticas de expatriação. Para a segunda fase, buscouse selecionar empregados de diferentes países, com diversos tempos de expatriação. Parte das entrevistas foi realizada presencialmente, em sala particular, em duas unidades da empresa, no estado do Rio Grande do Sul. Optou-se por essas unidades em função da proximidade, facilitando, portanto, o contato com a empresa e os expatriados.

Com os expatriados que estavam fora do país, as entrevistas foram realizadas via internet, com ferramentas de conversação, como MSN e Skype. Além de possibilitarem a interação entre entrevistador e entrevistado, elas permitem o contato visual, evitando a perda da percepção das expressões dos entrevistados ao falarem sobre expectativas, desafios e dificuldades enfrentadas. Além disso, essas ferramentas são familiares aos entrevistados, por serem seus principais meios de comunicação com o Brasil.

Para as entrevistas do Grupo 4, em função de a empresa não divulgar os nomes de ex-empregados, foi feito o contato com um entrevistado que participou do pré-teste, mas que deixou a empresa três meses depois de participar da entrevista, o qual indicou os demais entrevistados desse grupo. Essas entrevistas foram realizadas nos seus novos locais de trabalho.

Para a análise de dados coletados nas entrevistas, foi utilizada a técnica de análise de conteúdo que tem o intuito de descobrir e ir além da transparência dos dados (BARDIN, 2009). Em um primeiro momento, realizou-se a transcrição das entrevistas e, diante das entrevistas digitadas, foi realizada uma leitura flutuante, a fim de estruturar as categorias. Dessa maneira, foi realizado um recorte dos parágrafos em comum e estes foram organizados dentro de três categorias: (1) adaptação do repatriado e o papel do $\mathrm{RH}$, (2) expectativas: recolocação do 
empregado, perspectivas de crescimento e a carreira após a expatriação e (3) significado da missão para os expatriados e repatriados.

Após a categorização concluída, foi realizada a interpretação dos dados e da relação com a literatura utilizada neste trabalho. Cabe destacar que este artigo apresenta um recorte de uma dissertação mais ampla, na qual também foram discutidas a expatriação (preparação para expatriar e o papel do $\mathrm{RH}$; família: participação no processo; trabalho e desempenho: perfil para expatriar; adaptação e o impacto do grupo; e significado da expatriação) e a relação desses processos com a carreira (percepção sobre carreira; planejamento da carreira; expectativa de carreira; e relevância da expatriação na carreira).

\section{Analisando a repatriação na empresa Alpha}

Esta seção encontra-se estruturada nos seguintes tópicos: (1) a área de $\mathrm{RH}$ da empresa Alpha, na perspectiva dos expatriados, a fim de melhor contextualizar o caso e entender o processo dentro das estratégias da empresa; (2) o papel do RH na adaptação do repatriado; (3) o significado da missão para os expatriados e repatriados; (4) expectativas: recolocação do empregado, perspectivas de crescimento e a carreira após a expatriação; e (5) os desafios para a área de $\mathrm{RH}$.

\subsection{A área de RH da empresa Alpha, na perspectiva dos expatriados}

A empresa pesquisada tem mais de seis mil empregados no estado e 13 mil empregados distribuídos em oito países (Brasil, Colômbia, México, Argentina, África do Sul, Egito, China, Índia). Com isso, a demanda por executivos em cargos de gerência, em diversas partes do mundo nas quais atua, é alta. O programa de expatriação iniciou-se há 12 anos e, atualmente, conta com cerca de 90 expatriados que foram convidados a assumir os desafios de uma carreira internacional.

O Quadro 2 mostra o perfil dos expatriados entrevistados, a fim de mostrar as características comuns entre eles. Destaca-se que a maioria 
dos entrevistados foi do sexo masculino (O que constitui a maioria dos expatriados na empresa), com predomínio de pessoas com experiência internacional anterior (expatriação anterior ou viagens de negócios). 0 tempo de casa variou de 4 a 34 anos (média de tempo de casa: 13 anos) e a faixa etária estendeu-se de 27 a 62 anos (13 entrevistados encontravam-se na faixa de 39 a 52 anos).

Quadro 2 - Resumo do Perfil dos Entrevistados

\begin{tabular}{|c|c|}
\hline Categorias & Características \\
\hline $\begin{array}{l}\text { 1. Perfil dos expatriados } \\
\text { entrevistados }\end{array}$ & $\begin{array}{l}\text { - Escolaridade superior (18 entrevistados) } \\
\text { - Faixa etária elevada (média de idade: } 41 \text { anos) } \\
\text { - Tempo de casa elevado ( } 13 \text { anos) } \\
\text { - Sexo masculino (19 expatriados) } \\
\text { - Possuem experiência internacional anterior (12 } \\
\text { entrevistados) }\end{array}$ \\
\hline 2. Família & - Esse fator não influencia a escolha do candidato \\
\hline 3. Países de expatriação & - Índia é o país que mais demanda expatriados \\
\hline 4. Tempo do contrato & - Em média, a expatriação tem duração de 2 anos \\
\hline 5. Cargo & $\begin{array}{l}\text { - A maioria retorna para um cargo similar ao que tinha } \\
\text { antes da expatriação }\end{array}$ \\
\hline
\end{tabular}

Fonte: Elaboração dos autores (2013)

Hoje, a empresa está presente em mais de 100 países dos cinco continentes e sua estrutura possibilitou-lhe ter $8 \%$ do mercado global. Ela está posicionada entre as maiores fabricantes do mundo e, em relação ao mercado brasileiro, é líder em seu segmento. Devido a sua representatividade no mercado e a sua internacionalização, foi escolhida para a realização desse estudo. A busca da empresa por novas ferramentas para aperfeiçoar o processo de expatriação proporcionaram os elementos necessários para a consecução desta pesquisa.

$\mathrm{Na}$ perspectiva da área de $\mathrm{RH}$, a repatriação acontece quando o contrato envolvendo a experiência internacional da pessoa termina. Entretanto, por vezes, embora o contrato tenha terminado, ele pode ser renovado por alguns meses até que seja encontrada uma pessoa para assumir o cargo no exterior, se necessário. Quando o repatriado retorna, 
o acompanhamento dessa pessoa fica sob responsabilidade do superior imediato, mas a área de $\mathrm{RH}$ se responsabiliza pela documentação envolvida.

A Entrevistada $V$ observa que quando os expatriados desejam antecipar seu retorno para o Brasil por algum problema, não são criados empecilhos. O contrato de expatriação é um contrato de intenções e prevê que se a pessoa tiver problemas durante sua missão, ela deve entrar em contato com a empresa para que seja verificada a melhor possibilidade de ajudá-la, não havendo penalidades financeiras em função do retorno precoce. No caso de o expatriado retornar e desejar sair da empresa, também não há impedimentos nem penalidade financeira.

Com relação ao plano de carreira, a Entrevistada $U$ aponta que não há nada previsto no contrato envolvendo perspectivas de promoção. Algumas vezes acontece de serem discutidas formas de crescimento com o próprio gestor que fez o convite. Ou seja, são levantados e discutidos os ganhos que a pessoa terá pelo conhecimento agregado, mas nada é formalizado no contrato.

De maneira geral, as entrevistadas relatam que o objetivo da empresa com o processo de expatriação é levar o conhecimento da matriz para a subsidiária, e não o desenvolvimento do empregado. Assim, o foco estratégico da empresa está na missão, e não no retorno da pessoa.

\subsection{Papel do RH na adaptação do repatriado}

Os entrevistados observam que a estrutura da empresa para receber os repatriados ainda carece de algumas práticas. Uma das mais citadas é a recolocação do repatriado em seu novo ambiente de trabalho, como também é apontado no estudo de Suutari e Brewster (2003). Consideram que a empresa não tem um planejamento eficiente para a volta dessas pessoas, o que acaba por desmotivá-las, pois, sem maior planejamento, são colocadas em um cargo referido como "qualquer". Entretanto, os entrevistados apontam que dificilmente serão desligados da empresa, pois há certa tolerância da organização e dos colegas com as dificuldades de readaptação a seu novo trabalho. 
Os entrevistados do Grupo 1 (que estão no início da expatriação) observam que terão de aprender as mudanças ocorridas na empresa, como mudanças no produto e em procedimentos, enquanto estiveram fora da matriz, sendo importante que hajam canais de comunicação eficazes. Ressaltam também a questão dos relacionamentos com os colegas, pois, em função da rotatividade da empresa e da demanda por novas expatriações, alguns contatos internos são perdidos. Isso influencia a intraculturalidade apontada por Craide et al (2010), na qual as organizações precisam ter práticas para gerir esse "novo indivíduo" e a sua aprendizagem, bem como os empregados de diferentes culturas.

Aqueles expatriados que têm mais convívio com a empresa matriz, em função das viagens de negócios realizadas ao Brasil, acreditam que terão menor dificuldade de adaptação no trabalho. Essas viagens são diferentes daquelas que a empresa oferece a todos os empregados em forma de férias, pois permitem que o expatriado, normalmente de cargo superior, tenha contato com os clientes e com o produto, e isso faz com que a pessoa continue tendo contato com o dia a dia da empresa. Essa prática poderia ser aplicada com todos os expatriados, para que eles não fiquem tão deslocados no retorno para a matriz.

Outro tema que se refere às práticas de $\mathrm{RH}$ trazido pelos entrevistados envolve a questão da readaptação familiar quando da volta ao Brasil. Há relatos ilustrando que a área de $\mathrm{RH}$ não demonstra preocupação em saber como o repatriado está se adaptando e se ele ou sua família está precisando de algum auxílio. Dessa maneira, caso o empregado esteja passando por alguma dificuldade, a empresa dificilmente ficará sabendo, a menos que a pessoa a procure para falar sobre isso. Nos casos em que o repatriado solicita suporte da empresa, percebe-se a fragilidade da área, pois a ajuda é reportada a algum gerente ou supervisor para que este leve o problema aos superiores. Como a empresa não possui uma área específica de atendimento a esses casos, o repatriado não tem a quem se reportar dentro da área de $\mathrm{RH}$. 
Há de se considerar que, assim como o repatriado, a família também passa por uma fase de readaptação social, por ter ficado afastada do Brasil por certo tempo. Os filhos enfrentam uma mudança do sistema educacional, que varia de país para país. A esposa pode ter desistido de seu emprego e encontrar-se afastada de contatos profissionais. Os repatriados percebem que o reajuste da família é mais delicado do que o deles. É observado que o repatriado volta para seu dia a dia na empresa e, apesar das dificuldades, acaba retomando seu antigo contexto.

Aqueles que deixaram a família no Brasil ressaltam que, assim como a empresa colocou outra pessoa em seu cargo, a qual teve que aprender a trabalhar sem sua presença, a família também aprendeu a viver sem o expatriado. $\mathrm{O}$ Entrevistado $\mathrm{J}$ relata que a família dele construiu um novo cotidiano, do qual ele não fazia mais parte. Quando retornou, após três anos, percebeu que sua família não dependia dele e que sua esposa absorvera o papel de pai.

Com relação à estrutura do $\mathrm{RH}$, não houve diferença de percepção entre os grupos pesquisados, apesar de dois expatriados acreditarem que não é responsabilidade do RH apoiar a família. De modo geral, os procedimentos destacados positivamente dizem respeito mais às práticas de expatriação do que de repatriação propriamente dita, sendo comuns a todos os grupos entrevistados (auxílio de documentação, benefícios, preparação da língua, entre outros), bem como as falhas (apoio à família, preparação para o retorno, gestão de carreira, entre outros).

\subsection{Significados da missão para os expatriados e repatriados}

Apesar dos problemas ressaltados, os repatriados observam que a volta tem um significado de "dever cumprido", mostrando que eles corresponderam às expectativas da empresa em relação à sua competência. A volta permite que eles repensem sua vida e comecem a dar valor a outros aspectos, como cuidar mais da família, dar menos importância ao dinheiro, aproveitar mais a vida e desperdiçar menos coisas, como água e comida. Assim, a repatriação tem um significado 
de mudança de valores e traz a possibilidade de colocar em prática essa mudança. Há também significados mais relacionados ao nível profissional, como satisfação pelo bom desempenho, sensação de competência, perda de autonomia, e crescimento, tanto dentro como fora da empresa. De modo geral, não há diferença entre os grupos pesquisados. Inclusive os expatriados que estão no início da expatriação (Grupo 1) já observavam as questões citadas.

Esses significados mostram que o conceito de expatriação é mais do que a simples transferência de um empregado, como apontam Dutra (2002) e Caligiuri (2000). Ela está relacionada com a mudança de hábitos, rotinas, costumes, valores pessoais e a construção de uma nova rede de relacionamentos, tanto para a pessoa que está sendo expatriada como para sua família.

Conforme os relatos, a repatriação possibilita, entre vários aspectos citados, a ampliação de perspectivas de trabalho e de vida, o desenvolvimento de novas competências e habilidades, o reconhecimento pelo trabalho realizado, especialmente a partir do feedback dos superiores. É interessante que o desenvolvimento do empregado não é o objetivo principal da empresa. Ela busca levar o conhecimento para fora do Brasil e não tem mostrado interesse em aproveitar o conhecimento que os expatriados trazem para a matriz. Isso demonstra uma certa incoerência, visto que o processo de expatriação é de alto custo e a empresa deveria buscar otimizar os benefícios dessa experiência.

\subsection{Expectativas: recolocação do empregado, perspectivas de crescimento e a carreira após a expatriação}

Uma das expectativas mais mencionadas pelos entrevistados foi relativa à carreira, muito em função de a experiência da expatriação envolver os sentimentos comentados. A autonomia para tomar maiores decisões é, aparentemente, um dos maiores ganhos com a expatriação. Como Tanure et al. (2007), Black e Gregersen (1999), Lazarova e Caligiuri (2001) e Suutuari e Brewster (2003) observam que, em alguns casos, a 
autonomia que o expatriado tem na expatriação acaba se transformando em uma recusa de regresso, por perceber maiores possibilidades de trabalho no exterior do que no país de origem. Esse também é indicado como um dos fatores de insucesso de uma repatriação (BLACK; GREGERSEN, 1999; TANURE et al., 2007). Os repatriados sabem que podem desenvolver atividades mais complexas do que aquelas que estão fazendo, entretanto, a empresa não Ihes atribui tais atividades e responsabilidades desafiadoras como as tidas na missão.

Um dos diretores da empresa, quando questionado sobre a recolocação, observou que isso acontece naturalmente e que o retorno do desempenho vem com o tempo, citando como exemplo o Entrevistado L (Grupo 3), que foi bem recolocado. Entretanto, esse observou que "hoje, mais do que antes [penso em sair da empresa]", em função dos motivos citados anteriormente. Isso mostra que a empresa, por não fazer o acompanhamento dos repatriados, não tem noção do posicionamento deles e, frequentemente, sua visão é diferente da visão do expatriado.

No caso estudado, repetidamente, a repatriação é vista também como "questão de sorte", como observa o Entrevistado N. Atualmente, as repatriações com mais sucesso são aquelas em que o expatriado que está voltando fica no cargo da pessoa que está sendo expatriada, ou seja, há uma troca de lugares no Brasil e no exterior. Essa prática é denominada "troca casada".

O depoimento do Entrevistado $\mathrm{J}$ ilustra como a maioria das repatriações ocorre na empresa. Os empregados saem sem data certa para voltar, em função da missão. Isso ocorre não necessariamente pela falta de planejamento da missão, entretanto, acaba influenciando a realocação na empresa matriz (até que a empresa não tenha certeza de que o empregado vai ficar no Brasil, não tem como realocá-lo). Frequentemente, ele é realocado não na função desejada e, algumas vezes, leva muito tempo para que essa recolocação ocorra. A empresa não possui uma comunicação eficiente para chegar até o empregado e explicar-lhe a situação, repassando essa função para os gestores, os quais não têm consciência sobre essa atribuição do cargo. 
A gente chega aqui na fábrica e o lugar que você deixou foi ocupado, e as pessoas que te recebem, tem a consciência de que você está voltando e que você precisa ser absorvido (...) a gente não sai de lá com data, a gente não viaja com data definida, não tem data para voltar também. Você fica lá: "bom talvez volte, talvez não volte, talvez fique mais um pouco" (...) então, quando a gente chega aqui, as pessoas tem que te ver chegar, "agora chegou, então, agora sim eu posso contar com ele para fazer o meu projeto". [...] Eu cheguei aqui e as vagas estavam ocupadas e as pessoas que mais te conhecem muitas vezes ainda não chegaram. Você fez um trabalho bom lá fora e esses meninos que trabalharam comigo também, e quando chego aqui com a gurizada comigo (...) mas o supervisor, o gerente ou o coordenador que está recebendo eles de volta veem eles iguais a qualquer outro, ou menos porque eles vão ter que chegar e conquistar seu lugar. Então, para variar, alguns chegaram e tiveram um encaixe imediato e outros chegaram e ficaram remando, remando. Com certeza, a gente sempre disse pra eles: "não se preocupem, você tem lugar, você é importante e capacitado e vai ser encaixado", mas até ajustar, já tinha passado meses e alguns deles ainda não estão plenamente acertados. Felizmente, eu conheço a história de todos eles, sei onde cada um está e o que está fazendo. Só que tem uma coisa que por mais que a gente fale, a gente não é preparado pela empresa, mas eu conversei muito com eles [...] a empresa tem que ter um trabalho de maior aproximação, para preparação da pessoa para sair, e um trabalho de reabsorção, de reinclusão. Não é a questão da colocação dele na fábrica só, mas é o dele se sentir com valor. Ele entende o processo, todos entendemos que tem que vir e abrir o espaço dele, se encaixar, todos entendemos isso, mas ninguém pode se sentir abandonado, desprestigiado, e isso acontece (ENTREVISTADO J - GRUPO 3).

Quanto ao cargo assumido, é ressaltado que ele não é importante, e $\operatorname{sim}$ as atividades e responsabilidades a serem desenvolvidas no 
exercício do cargo, pois os entrevistados não querem ficar "jogados em um canto até que seja arrumado algo para fazer" (Entrevistado P - Grupo 3). Para o Entrevistado A (Grupo 1), é importante "voltar para empresa dentro de alguma área que eu possa fazer sentido. Eu não quero só encher linguiça, 'ah, não vamos despedir, mas vamos colocar aqui por enquanto e depois a gente vê'”. A nomenclatura do cargo não importa para eles, e sim os desafios e as atividades realizadas. Até mesmo aqueles que voltaram como gerentes se dizem insatisfeitos com seu cargo, por não receberem desafios e verem "que lá fora as coisas acontecem e aqui não", como disse o Entrevistado L (GRUPO 3), referindo-se à forma engessada que a empresa possui.

O índice de desligamento da empresa, após a repatriação, vem aumentando, o que sinaliza falhas na repatriação. As práticas adotadas pela empresa são reagentes aos problemas, e não de suporte, o que vai ao encontro dos achados nos estudo de Lima e Braga (2010). A frequência da expressão "quando tu vais, tu és a solução de um problema. Quando tu voltas, tu és o problema” (Entrevistado Q - Grupo 4) reflete que a empresa não está atenta para receber o empregado de volta, provocando a visão de que o repatriado se torna um problema.

O Entrevistado $Q$ observa que o crescimento internacional da empresa está paralisado no momento em função da falta de empregados qualificados, dispostos a viajar. Nesse sentido, Black e Gregersen (1999), Lee e Liu (2006) e Tanure et al. (2007) analisam que, quando a expatriação começa a ser vinculada a aspectos negativos, como demissão do trabalhador, problemas de adaptação e falta de perspectiva de crescimento, outras pessoas podem começar a rejeitar a missão.

Dentro dos aspectos observados pelos citados autores, os entrevistados dos Grupos 1 e 2 não sabem como será sua repatriação, mas a percepção que eles têm, considerando outros colegas que já passaram por isso, não é positiva. Entrevistados de outros grupos relatam que, quando estavam em expatriação, tinham perspectiva semelhante às dos Grupos 1 e 2. Assim, a falta de práticas, políticas e pessoas que implementem uma repatriação mais adequada na empresa vem causando desmotivação nos expatriados. 
Nesse contexto, o Grupo 1 (que está no início da expatriação) questiona como vai ser seu futuro, pois não há um posicionamento da empresa matriz sobre a recolocação. Independentemente do Grupo analisado, o feedback recebido dos superiores na missão, sinalizando que o trabalho realizado atingiu os objetivos da empresa e que o expatriado, no que depender da opinião desses supervisores, será recompensado por isso, na empresa matriz, cria expectativas de crescimento. Essas informações, entretanto, não chegam ao $\mathrm{RH}$, pois a área não possui um controle de gestão de desempenho dos expatriados que supra as necessidades da empresa nem há comunicação entre os superiores do expatriado para saber qual foi o seu desempenho na missão.

Outro fator ressaltado é que a empresa não possui uma política aplicada a todos os empregados. Os gerentes tomam decisões nas quais acreditam ser melhor para cada empregado, resultando em tratamento diferenciado a cada um. O Entrevistado B tenta fazer o que acha melhor para seus subordinados, mas isso não significa que essa seja a melhor forma. Como a empresa não solicita isso de todos os gestores, o tipo de atitude que ele toma não é valorizado. Novamente, a informalidade das práticas de expatriação mostra a ausência de uma área de GRHI ativa.

No Grupo 4 (repatriados que não se encontram mais na empresa), ao serem questionados sobre a saída da empresa, somente o Entrevistado $\mathrm{R}$ disse que seu desligamento não teve relação com a repatriação, pois o motivo que levou à sua saída foi "a oportunidade [de ter o seu próprio negócio]". Os outros entrevistados desse mesmo grupo relataram que, depois da repatriação, perceberam que seus objetivos não se encaixavam mais com os da empresa e seu cargo não apresentava mais desafios para eles. Os desafios, a divergência de visão entre empregado e empresa, e a autonomia dos repatriados são bastante ressaltados como importantes fatores para a saída dos repatriados das organizações (TUNG, 1988).

Quanto ao Grupo 3 (repatriados que ainda estão na organização), dos sete entrevistados, quatro falaram já ter pensado em sair da empresa após uma das suas repatriações. Os que saíram da empresa (Grupo 4) 
observaram que procuraram conversar com seus gestores, mostrando insatisfação com o cargo, e que a decisão de desligamento da empresa não foi repentina. Eles explicaram que, quando voltaram da expatriação, mantiveram seus currículos profissionais atualizados e os enviaram para outras empresas.

A questão de recolocação é uma preocupação desde o início da viagem, pois o contrato apenas estabelece que o empregado volta para um cargo similar ao que ele tinha antes da expatriação, não informando em qual o departamento ou área. O fator que chama atenção é que a diferença de percepção não está entre os grupos, mas pelo tempo de empresa e a idade que os pesquisados têm. Os expatriados mais jovens e com menos tempo de empresa têm uma percepção de "carreira sem fronteiras" (LAZAROVA; CALIGIURI, 2001) e acreditam que se não se sentirem bem na empresa, procurarão outra organização que valorize seu aprendizado. Já os expatriados mais velhos e com mais tempo de empresa valorizam a cultura familiar e tradicional da organização e buscam alternativas dentro da empresa Alpha.

\subsection{Os desafios para a área de RH}

A falta de clareza por parte da empresa ou mesmo a inexistência de definições sobre esse processo para que a missão seja realizada com sucesso é referida por Tanure et al. (2007), pois é necessário que os empregados saibam o que a empresa espera deles e para onde irão quando voltarem. $\mathrm{O}$ aumento da divergência de expectativas da empresa com a dos empregados, já que estes não sabem qual é a expectativa da empresa, dá oportunidades para que os expatriados criem expectativas maiores do que o que a empresa tem a lhes oferecer.

Pode-se perceber que, em função de todo um investimento pessoal e profissional realizado pelos profissionais que aceitam a missão internacional, somada a uma glamorização da mobilidade (FREITAS, 2009), é criada uma expectativa de reconhecimento pela empresa, visto que empresa deixa claro que não há perspectiva de crescimento na repatriação. De todo exposto, a empresa é coerente com 
a sua política, entretanto, as expectativas dos empregados em busca do reconhecimento do trabalho desenvolvido, acabam ultrapassando os contratos formais com a empresa. Cabe mostrar que a organização deve ser mais eficiente no reconhecimento do trabalho, promovendo as pessoas que desenvolveram um bom trabalho para não perder esse conhecimento. Assim, uma das práticas necessárias é a gestão de avaliação de desempenho (REGO; CUNHA, 2009), a qual foi citada como inexistente.

A utilização do aprendizado proveniente da expatriação, tal qual relatado, não é percebido enquanto preocupação da empresa. Em alguns casos, entretanto, esse aproveitamento acontece. O Entrevistado M, que está voltando da expatriação em uma posição estratégica da empresa, observa que essa falha existe, mas que aproveitar melhor o conhecimento dos expatriados é um de seus objetivos. Independentemente do grupo em que se encontram os entrevistados, nota-se que os expatriados têm as mesmas expectativas quanto à recolocação: assumir um cargo no qual possam desenvolver o que aprenderam.

Assim, cria-se uma ilusão em torno de uma maior valorização dos repatriados, desejada através do exercício de atividades desafiadoras no retorno da experiência vivida. Tal questão pode ser relacionada a uma abertura para o mundo, uma necessidade, um requisito das organizações (FREITAS, 2009; TUNG, 1998). No caso da empresa em questão, foi identificado como principal objetivo da expatriação a necessidade de levar conhecimento para as empresas subsidiárias e ter pessoas de confiança para o gerenciamento das unidades. Cumprida a missão, há o retorno sem maiores garantias - apenas a de que é necessário estar sempre aberto e em movimento.

Com 12 anos do programa de expatriação, a internacionalização cresceu rapidamente dentro da empresa. Aorganização foi se expandindo para outros países, por oportunidades de mercado visualizadas, mas a cultura da empresa continua centrada localmente e nos processos que acontecem somente no Brasil. 
A área de $\mathrm{RH}$, tendo tamanho reduzido e estrutura tradicional, passou a ter dificuldades em dar o suporte necessário para os expatriados. A expatriação é uma das 10 subdivisões da área de $\mathrm{RH}$ (folha de pagamento, cargos e salários, comunicação interna, expatriados, recrutamento interno, formação e desenvolvimento, medicina ocupacional, segurança do trabalho, benefícios e serviço social). Nessa subárea, há apenas três pessoas, e somente uma exerce função exclusiva na expatriação/repatriação para gerenciar dezenas de repatriados. Com isso, a área de expatriação assume caráter burocrático, com pequeno espaço para ações mais estratégicas, fatores também descritos no estudo de Lima e Braga (2010).

Entende-se aqui que a expatriação é um processo maior do que a simples transferência de pessoas de uma subsidiária para outra, na medida em que influencia diretamente na forma de condução dos negócios, bem como na própria expansão internacional. Na literatura, poucos estudos trazem o enfoque estratégico que a expatriação tem, podendo, assim, impactar no desenvolvimento internacional da empresa.

Assim, vários desafios surgem para a organização: o melhoramento da imagem da repatriação, a qual tem sido prejudicada por repatriações mal sucedidas; maior receptividade e acompanhamento dos repatriados; oportunidade de atualização para o repatriado a respeito das mudanças ocorridas em sua ausência. Outro deles é o planejamento da repatriação, que inclui aproveitamento das habilidades desenvolvidas pelos empregados na missão, avaliação do desempenho e retenção dos repatriados. Há ainda a comunicação sobre a ida e vinda dos expatriados, bem como a melhora da comunicação, envolvendo matriz, subsidiária e expatriado.

\section{Considerações finais}

O processo de internacionalização das empresas brasileiras ainda é considerado incipiente e lento, o que motiva os estudos sobre esse tema (SCHERER, 2012). A expatriação, embora ainda não tenha tal destaque na literatura, auxilia no desenvolvimento internacional das 
empresas. Caso contrário, sem os expatriados, dificilmente uma empresa alcançaria níveis de maturidade de internacionalização tão facilmente.

Para tanto, esta pesquisa analisou a etapa da repatriação e os desafios que as empresas enfrentam no retorno do expatriado. Apesar de essa etapa representar o fim da experiência internacional, este estudo ressalta a importância da repatriação em função de que, a partir do feedback dos empregados, novas estratégias de internacionalização podem ser traçadas. Assim, a expatriação como um processo amplo não é o simples deslocamento de um empregado, e sim a aquisição de conhecimento tanto para a empresa como para o indivíduo. Além disso, há pouca literatura que discuta essa etapa, bem como os atuais estudos geralmente concentram-se nos problemas familiares e na adaptação cultural dos expatriados.

Entre os principais resultados, verificou-se que a empresa em estudo, apesar de ter um programa de expatriação há 12 anos, ainda há espaço para o desenvolvimento de políticas e práticas mais estruturadas. Tal fato se deve ao fato de que a internacionalização acabou tomando uma dimensão maior do que a organização estava preparada para enfrentar. $\mathrm{A}$ área de $\mathrm{RH}$, por sua estrutura mais tradicional, não está conseguindo acompanhar e construir práticas e políticas que supram a real necessidade da empresa. A organização, entretanto, está procurando conhecer e compreender melhor a realidade que envolve expatriados e repatriados, inclusive oportunizando esse estudo.

Analisando a repatriação, sob a perspectiva profissional e considerando o caso estudado, percebe-se que um dos problemas está na relação construída entre expatriação e carreira. Os empregados, com a experiência vivenciada, acabam exercendo atividades mais amplas e têm maior autonomia, mas, quando retornam ao Brasil, na maior parte das vezes voltam a exercer as mesmas atividades que tinham anteriormente. Há, assim, frustração devido à redução de responsabilidades e desafios em face de todo o investimento pessoal e profissional realizado.

Entretanto, uns dos principais ganhos apontados pelos entrevistados foram a aprendizagem de vida e o desenvolvimento da 
carreira sob a perspectiva do indivíduo, ou seja, eles passam a valorizar a carreira interna (STAHL et al., 2002), que agrega conhecimento e diferencial competitivo ao empregado, independentemente da organização da qual fazem parte.

Em termos de práticas, poderia-se desenvolver mais com a 'troca casada' para enviar um expatriado e, simultaneamente, recolocar um repatriado em um cargo com desafios maiores, porém istoainda precisa ser planejado. Como desafios, se têm a melhora da imagem da repatriação; maior receptividade e acompanhamento dos repatriados; atualização do repatriado sobre as mudanças da empresa em sua ausência; melhoramento do planejamento da repatriação; aprimoramento da avaliação do desempenho durante a experiência internacional; e retenção dos repatriados. De todo exposto, depreendese que o valor da expatriação ainda não está devidamente reconhecido nessa organização, empresa que ainda não possui uma visão estratégica envolvendo recursos humanos.

Um fator a ser ressaltado é a questão da avaliação de desempenho dos expatriados, prática enfatizada por Rego e Cunha (2009). Todos os entrevistados relataram que voltaram para o Brasil como 'pessoas melhores', tanto no contexto profissional como no individual. Entretanto, a organização não possui um panorama sobre isso, por nãoutilizar, com eficiência,da gestão de desempenho no que se refere aos expatriados, no sentido de acompanhar seu aperfeiçoamento e verificar quais oportunidades de crescimento dentro da organização caberiam a cada um.

Outro fator de destaque é que a estratégia da empresa está em levar o conhecimento para fora do Brasil, logo, o conhecimento trazido pelos expatriados não faz parte de sua estratégia, fato ressaltado pela pesquisa de Lima e Braga (2010), que observa ser um perfil comum, embora não seja o ideal, das empresas brasileiras. Isso se reflete na postura, atuação e abertura que a área de $\mathrm{RH}$ tem em relação à expatriação. Lima e Braga (2010) abordam a "miopia" da área, pois não conseguem identificar as perdas de capital humano que as organizações 
acarretam quando perdem um expatriado. No entanto, cabe questionar se esta é uma falha exclusiva da área de $\mathrm{RH}$ ou da empresa como um todo. A dificuldade de se ter políticas e práticas para os processos de RH não necessariamente pode ser visto como uma negligência da área. Muitas vezes, está relacionada com a importância que a empresa dá para os seus processos e permite que a área de $\mathrm{RH}$ mostre a diferença que ela pode fazer dentro da empresa. Isso mostra que a problemática do RH ultrapassa suas políticas e práticas, pois envolve a maneira como a área está posicionada estrategicamente na organização e a maneira que ela atua para ter tal destaque.

Ademais, como a organização não valoriza o conhecimento trazido na repatriação, o RH acaba não incorporando ações para essa prática. Se é o fim de um processo, por que haveria necessidade de se ter práticas e políticas? A área possui um papel estratégico na organização e que, com a implementação de políticas e práticas articuladas ao plano estratégico, ela se torna indispensável para o desenvolvimento global da empresa.

A ausência de um modelo de expatriação que contemple as fases e práticas de expatriação corrobora para a dificuldade em se ter um planejamento desse processo, o que impede a visualização do conhecimento que envolve cada fase do processo. Muitas vezes, o objetivo da expatriação é o de levar o conhecimento, como uma via de mão única, e, consequentemente, o foco da expatriação é na missão em si, tornando a repatriação o fim de um ciclo, sem maiores contribuições. A repatriação é o término da experiência internacional, mas, ao mesmo tempo, também é o recomeço para traçar novas estratégias por meio do conhecimento obtido durante este processo. O conhecimento trazido por uma repatriação auxilia tanto nas estratégias das organizações, pelo conhecimento do mercado, como na implementação de políticas e práticas de GRHI, ajudando a empresa a se tornar global. Entende-se que, com base no feedback da repatriação obtido por gestores da subsidiária e pelo próprio repatriado, novas deficiências e estratégias poderão ser encontradas bem como a necessidade de futuras expatriações. 
Por isso, neste estudo, destaca-se a importância do planejamento de todo o processo de expatriação, além de entender como esse processo pode contribuir para os objetivos da empresa. Ademais, enfatiza-se a fase da repatriação como suporte para traçar novas estratégias, por meio do conhecimento que esses empregados trazem, após a rica experiência que tiveram.

Este estudo procurou ainda contribuir ao apontar para a ilusão que, de certa forma, se cria em função da glamorização da expatriação. O discurso atual favorece a disseminação da mobilidade enquanto capital valorizado, assim como da necessidade de contínuo movimento na forma de empreendedorismo pessoal, que gera expectativas para os indivíduos em torno de suas carreiras (FREITAS, 2009). Com o retorno da missão internacional, espera-se que portas se abrirão na empresa, novos desafios serão vivenciados etc., o que nem sempre acontece, como no caso estudado, sendo sentido como falta de reconhecimento.

Esta pesquisa consistiu em um estudo de caso, portanto, não há como generalizar os resultados para todas as empresas que possuem um programa de expatriação. Detectam-se alguns aspectos que têm influência como fatores limitadores, por exemplo, o país para o qual o expatriado é enviado, pois, dependendo dos aspectos culturais do local e da estrutura da empresa, o processo pode se tornar uma experiência positiva ou negativa, sendo esse um fator que a empresa não tem como controlar. Além disso, destaca-se que, no caso da empresa em questão, a maioria dos expatriados é do sexo masculino e de diversos cargos (soldador, analista, gerente, coordenador e diretor). No entanto, os expatriados mais requeridos e com maior tempo de expatriação são dos cargos gerenciais, pois os cargos inferiores normalmente ocorrem em missões específicas e de curta duração.

Esta pesquisa pretendeu mostrar com mais amplitude o processo de expatriação, caracterizado como importante estratégia dentro das organizações, pois, muitas vezes, não há oportunidade para que se investigue como isso acontece realmente. Dessa maneira, evidenciouse a lacuna que existe entre expatriação e repatriação, pois esta acaba sendo "esquecida" pela empresa e "naturalmente ajeitada". 
Ainda há muito que se pensar sobre o papel do $\mathrm{RH}$ em relação às estratégias internacionais, principalmente para se evitar a situação relatada pelos entrevistados repetidas vezes: "nós vamos como a solução de um problema e voltamos como um problema". Ou seja, os expatriados são chamados para resolver um problema da empresa, mas, ao retornarem, voltam como um problema que não pertence à empresa, mas, a eles próprios.

Sob a perspectiva da carreira, também é oportuno aprofundar como as empresas buscam reter os expatriados e de que forma o conhecimento adquirido por eles é utilizado pelas organizações. Outro estudo pertinente seria o de buscar entender as questões de gênero em processos de expatriação e repatriação, visto que a diversidade de gênero vem sendo cada vez mais valorizada no âmbito organizacional.

\section{Referências}

BARDIN, L. Análise de conteúdo. 3. ed. Lisboa, Portugal: Edições 70, 2009.

BARRETOS, L. M. T. da S.; SILVA, M. P. da; FISCHER, A. L.; ALBUQUERQUE, L. G. de; AMORIM, W. A. C. de. Temas emergentes em gestão de pessoas: Uma análise da produção acadêmica. Rev. Adm. UFSM, Santa Maria, Rio Grande do Sul, v. 4, n.1, p. 215-232, mai./ago., 2011.

BIANCHI, E. M. P. G. Gestão e Carreira Internacional. Repatriação - construindo elos entre ciclos. In: ENCONTRO NACIONAL DOS PROGRAMAS DE PÓS-GRADUAÇÃO EM ADMINISTRAÇÃO, 35, 2011. Rio de Janeiro. Anais ... Rio de Janeiro, ANPAD, 2011. CD-ROM.

BLACK, J. S.; GREGERSEN, H. B. The Right Way to Manage Expats. Harvard Business Review, Boston, v. 77, p. 52-62, mar./abr.,1999.

BROOKFIELD GLOBAL RELOCATION SERVICES. Global Relocation Trens. 2010 Survey Report. Estados Unidos, 2010. Disponível em: <http://www.brookfieldgrs.com/insights_ideas/grts/grts_thanks.asp> Acesso em: 30 nov. 2010. 
CALIGIURI, P. M. Selecting expatriates for personality characteristics: a moderating effect of personality on the relationship between host national contact and cross-cultural adjustment. Management International Review, Alemanha, v. 40, n. 1, p. 61-80, 2000.

CRAIDE, A.; ABDALA, V. D.; BRITO, A. C. de. "Eu Vim de Lá, (Mas Ninguém Avisou!)": reflexões sobre estratégias de Gestão de Pessoas voltadas à interculturalidade. In: ENCONTRO NACIONAL DOS PROGRAMAS DE PÓS-GRADUAÇÃO EM ADMINISTRAÇÃO, 34, 2010. Rio de Janeiro. Anais ... Rio de Janeiro: ANPAD, 2010. CD-ROM.

DERESKY, H. Administração global: estratégica e interpessoal. Porto Alegre: Bookman, 2004.

DUTRA, J. S. Gestão de pessoas: modelo, processos, tendências e perspectivas. São Paulo: Atlas, 2002.

FONTENELLE, I. A. A Auto-Gestão de Carreira chega à Escola de Administração: o humano se tornou capital? Revista Organizações e Sociedades. Salvador, v. 14, n. 43, p. 71-90, out./dez. 2007.

FREITAS, M. E. A mobilidade como novo capital simbólico nas organizações ou sejamos nômades?. O\&S. Organizações \& Sociedade, Salvador, v.16, n.49, p. 247-264 - Abril/Junho, 2009.

FREITAS, M. E. de. Expatriação Profissional: o desafio interdependente para empresas e indivíduos. Revista Eletrônica Gestão e Sociedade, CEPEAD/UFMG, .v. 4, n. 9, Setembro/Dezembro 2010.

FREITAS, M. E. de; DANTAS, M. O Estrangeiro e o novo grupo. Revista de Administração de Empresas (RAE), São Paulo, v. 51, n. 6, p. 601608, nov/dez, 2011.

GALLON; S.; SCHEFFER, A. B. B. O processo de expatriação de executivos: uma análise dos desafios da repatriação a partir de um estudo de caso em uma empresa do sul do Brasil. In: CONGRESSO FRANCO-BRASILEIRO DE ADMINISTRAÇÃO DE EMPRESAS DE TOURS , 7, 2013. Tours/França, Anais... Tours/França: Faculté de Droit, d'Economie et des Sciences Sociales, 2013. CD-ROM 
HERMAN, J. L.; TETRICK, L. Problem-focused versus emotion-focused coping strategies and repatriation adjustment. Human Resource Management, v. 48, n. 1, p. 69-88, january-february, 2009. Diposnivel em: <http://onlinelibrary.wiley.com/doi/10.1002/hrm.20267/pdf>. Acesso em: 30 nov. 2010.

HOMEM, I. D.; DELLAGNELO, E. H. L. Novas formas organizacionais e os desafios para os expatriados. Revista de Administração de Empresas (RAE - eletrônica), São paulo, v. 5, n. 1, jan/jun, 2006.

LAZAROVA, M.; CALIGIURI, P. Retaining repatriates: The role of organizational support practices. Journal of World Business, v. 36, n. 4, p. 389-401, 2001.

LEE, H. W.; LIU, C. H. The Determinants of Repatriate Turnover Intentions: An Empirical Analysis. International Journal of Management., v. 23, n. 4, p. 751-762, 2006.

LIMA, M. B.; BRAGA, B. M. Práticas de Recursos Humanos do Processo de Repatriação de Executivos Brasileiros. Revista de Administração Contemporânea. v. 14, n. 6, p. 1031-1053, 2010.

MCCALL, M. JR.; HOLLENBECK, G. P. Desenvolvimento de Executivos Globais: as lições da experiência internacional. Porto Alegre: Bookman, 2003.

OSMAN-GANI, A. A. M.; HYDER, A. S. Repatriation readjustment of international managers: An empirical analysis of HRD interventions. Career Development International, v. 13, n. 5, p. 456 - 475, 2008.

PEREIRA, N. A. F.; PIMENTEL, R.; KATO, H. T. Expatriação e estratégia internacional: o papel da família como fator de equilíbrio na adaptação do expatriado. In: ENCONTRO NACIONAL DOS PROGRAMAS DE PÓS-GRADUAÇÃO EM ADMINISTRAÇÃO, 28, 2004. Curitiba. Anais ... Curitiba: ANPAD, 2004. CD-ROM.

REGO, A.; CUNHA, M. P. E. Manual De Gestão Transcultural De Recursos Humanos. Lisboa: Editora RH, 2009. 
SCHEIN, E. H. Career Anchors Revisited: Implications for Career Development in the 21st Century. Academy of Management Executive, v. 10, p. 80-88, 1996.

SCHERER, F. L. Como Empresas Consolidam a Presença em Mercados Estrangeiros? Considerações Sobre o Processo de Internacionalização. Rev. Adm. UFSM, Santa Maria, Rio Grande do Sul , v. 5, n. 3, p. 569588, set./dez., 2012.

STAHL, G. K.; MILLER, E. L.; TUNG, R. L. Toward a boundary less career: A closer look at the expatriate career concept and the perceived implications of an international assignment. Journal of World Business, v. 37, p. 216 - 227, 2002.

SUUTARI, V.; BREWSTER, C. Repatriation: Empirical evidence from a longitudinal study of career sand expectations among Finnish expatriates. International Journal of Human Resource Management, v. 14, n. 7, p. 1132-1151, 2003.

TANURE, B.; EVANS, P.; PUCIK, V. A Gestão de Pessoas no Brasil.: virtudes e pecados capitais. estudos de caso. Rio de Janeiro: ELSEVIER, 2007.

TAYLOR, S.; BEECHLER, S.; NAPIER, N. Toward an Integrative Model of Strategic International Human Resource Management. Academy of Management Review, v. 21, p. 959-985, 1996.

TUNG, R. L. Career Issues in International Assignments. The Academy of Management Executive, v. 11, n. 3, p. 241-244, 1988.

TUNG, R. L. American expatriates abroad: from neophytes to cosmopolitans. Journal of World Business, v. 33, n. 2, p. 125-144, 1998.

Artigo recebido em: 12/03/2014

Aprovado em: 25/06/2014 